\title{
Measurements of UV irradiance within the area of one satellite pixel
}

\author{
P. Weihs ${ }^{1}$, M. Blumthaler ${ }^{2}$, H. E. Rieder ${ }^{1,3,}$, A. Kreuter ${ }^{2}$, S. Simic ${ }^{1}$, W. Laube ${ }^{1}$, A. W. Schmalwieser ${ }^{5}$, J. E. Wagner ${ }^{1}$, \\ and A. Tanskanen ${ }^{4}$ \\ ${ }^{1}$ Inst. for Meteorology, Department Water-Atmosphere-Environment, Univ. of Natural Resources and \\ Applied Life Sciences (BOKU), Vienna, Austria \\ ${ }^{2}$ Division for Biomedical Physics, Innsbruck Medical University, Innsbruck, Austria \\ ${ }^{3}$ Inst. for Geography and Regional Research, Univ. of Vienna, Vienna, Austria \\ ${ }^{4}$ Finnish Meteorological Inst., Helsinki, Finland \\ ${ }^{5}$ Inst. of Medical Physics and Biostatistics, Univ. of Veterinary Medicine, Vienna, Austria \\ *now at: Inst. for Atmospheric and Climate Science, ETH Zurich, Zurich, Switzerland
}

Received: 3 January 2008 - Published in Atmos. Chem. Phys. Discuss.: 22 February 2008

Revised: 1 August 2008 - Accepted: 19 August 2008 - Published: 23 September 2008

\begin{abstract}
A measurement campaign was performed in the region of Vienna and its surroundings from May to July 2007. Within the scope of this campaign erythemal UV was measured at six ground stations within a radius of $30 \mathrm{~km}$. First, the homogeneity of the UV levels within the area of one satellite pixel was studied. Second, the ground UV was compared to ground UV retrieved by the ozone monitoring instrument (OMI) onboard the NASA EOS Aura Spacecraft. During clear-sky conditions the mean bias between erythemal UV measured by the different stations was within the measurement uncertainty of $\pm 5 \%$. Short term fluctuations of UV between the stations were below $3 \%$ within a radius of $20 \mathrm{~km}$. For partly cloudy conditions and overcast conditions the discrepancy of instantaneous values between the stations is up to $200 \%$ or even higher. If averages of the UV index over longer time periods are compared the difference between the stations decreases strongly. The agreement is better than $20 \%$ within a distance of $10 \mathrm{~km}$ between the stations for $3 \mathrm{~h}$ averages. The comparison with OMI UV showed for clear-sky conditions higher satellite retrieved UV values by, on the average, approximately $15 \%$. The ratio of OMI to ground measured UV lies between 0.9 and 1.5 . and strongly depends on the aerosol optical depth. For partly cloudy and overcast conditions the OMI derived surface UV estimates show larger deviation from the ground-based reference data, and even bigger systematic positive bias. Here the ratio OMI to ground data lies between 0.5 and 4.5. The average difference between OMI and ground measurements is +24 to $+37 \%$ for partly cloudy conditions and more than $+50 \%$ for overcast conditions.
\end{abstract}

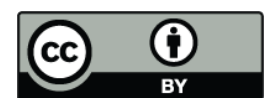

Correspondence to: P. Weihs

(philipp.weihs@boku.ac.at)

\section{Introduction}

During the last three decades global increases in UV fluxes resulting from decreasing stratospheric ozone have been an issue of public concern because of the direct linkage to human health (e.g. Scientific Committee on Problems of the environment SCOPE, 1992, 1993; United Nations Environmental Program UNEP, 1998; National Radiological Protection Board, 2002). A lot of effort has been done to understand the spectral UV climatology from ground-based measurements at different locations (WMO, 1995). Ground-based measurements are sparsely located and most of the nowadays available stations are in operation for 10 or 15 years. The longest UV radiation record from a ground-measurement station is available from the observatory Belsk in Poland dating back to 1978. Because of a lack in measurement data of UV in the past a lot of reconstruction studies for the UVpart of the spectrum (e.g. Kaurola et al., 2000; Lindfors and Vuilleumier, 2005; Koepke et al., 2006; Rieder et al., 2008) have been performed. The results of these studies show that surface UV radiation significantly increased during the last 20 to 30 years. Near surface UV measurements, reconstruction of past UV doses as well as the development of satellite derivation techniques have been among big scientific issues within the UV community during the last years. The Ozone Monitoring Instrument (OMI) is a nadir-viewing spectrometer that measures reflected and backscattered solar ultraviolet and visible light (Levelt et al., 2006). OMI is designed to measure atmospheric composition, and its measurements are used to continue the Total Ozone Mapping Spectrometer (TOMS) record of total ozone, aerosol and surface UV irradiance data. OMI is a Dutch-Finnish contribution to NASA's Earth Observing System (EOS) Aura mission. The Aura satellite was launched to a sun-synchronous afternoon orbit

Published by Copernicus Publications on behalf of the European Geosciences Union. 
Table 1. Information on ground-based stations used within this study.

\begin{tabular}{llll}
\hline Station & Station Code & Geographic Position & Altitude \\
\hline BOKU & 1 & $16^{\circ} 19^{\prime} \mathrm{E}, 48^{\circ} 14^{\prime} \mathrm{N}$ & $256 \mathrm{~m}$ a.s.l \\
STREBERSDORF & 2 & $16^{\circ} 23^{\prime} \mathrm{E}, 48^{\circ} 18^{\prime} \mathrm{N}$ & $175 \mathrm{~m}$ a.s.1 \\
TGM & 3 & $16^{\circ} 22^{\prime} \mathrm{E}, 48^{\circ} 13^{\prime} \mathrm{N}$ & $178 \mathrm{~m}$ a.s.l \\
GROSSENZERSDORF & 4 & $16^{\circ} 33^{\prime} \mathrm{E}, 48^{\circ} 12^{\prime} \mathrm{N}$ & $156 \mathrm{~m}$ a.s.l \\
BAD VOESLAU & 5 & $16^{\circ} 12^{\prime} \mathrm{E}, 47^{\circ} 57^{\prime} \mathrm{N}$ & $286 \mathrm{~m}$ a.s.l \\
UNIVERSITY VETERINARY MEDICINE & 6 & $16^{\circ} 25^{\prime} \mathrm{E}, 48^{\circ} 14^{\prime} \mathrm{N}$ & $166 \mathrm{~m}$ a.s.1 \\
\hline
\end{tabular}

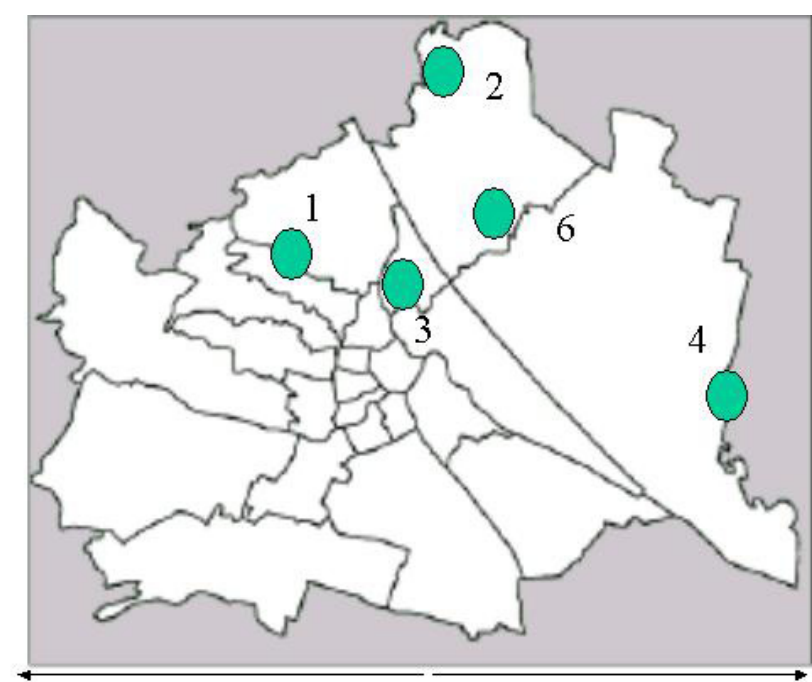

$25 \mathrm{~km}$

\section{5}

Fig. 1. Map of stations.

in July 2004, and since September 2004, OMI has provided nearly continuous global measurements of the composition of the Earth's atmosphere. OMI measures solar radiation in the spectral range of 270 to $500 \mathrm{~nm}$. The viewing angle of the instrument corresponds to a $2600 \mathrm{~km}$ wide viewing swath, which enables near-global coverage of the sunlit portion of the atmosphere. The spatial resolution of the instrument is $13 \times 24 \mathrm{~km}$ in nadir, but increases towards the edges of the swath. However, the majority of the pixels are smaller than $50 \times 50 \mathrm{~km}$. The OMI measurements are nominally made once per day in the afternoon around 01:45 p.m. local solar time. The OMI surface UV algorithm is largely similar to the algorithm originally developed by NASA/GFSC for the TOMS instrument (Tanskanen et al., 2006). However, while the original TOMS surface UV algorithm makes an aerosol correction based on the Aerosol Index, the current OMI surface UV algorithm does not include any correction for absorbing aerosols.
Thus, the OMI-derived surface UV data are anticipated to show some overestimation in the regions affected by absorbing aerosols or trace gases such as smoke from biomass burning, desert dust, or urban pollution. The satellite-derived surface UV data provided by TOMS measurements has been extensively validated by comparison with ground measurements (e.g. Kalliskota et al., 2000; McKenzie et al, 2001b; Fioletov et al., 2002; Chubarova et al., 2002; Cede et al., 2004; Arola et al., 2005; Kazantzidis et al., 2006). According to these studies the satellite derived surface UV data are 0 to $40 \%$ higher than ground-based data during snow free conditions. The validation of the TOMS data showed, that surface UV is highly underestimated at high latitude sites because seasonal snow is interpreted as thick clouds by the algorithms (e.g. Kalliskota et al., 2000; Krotkov et al., 2001, 2002). First validations also showed similar results for OMI (Tanskanen et al., 2007): in low polluted areas satellite UV daily doses were between 0 to $10 \%$ higher than ground-based data, in polluted areas satellite UV was up to $50 \%$ higher than ground-based measurements and for high latitude stations satellite UV was occasionally up to $50 \%$ too small because of unrealistically small albedo values used for the satellite UV calculations.

It has also been reported that the largest differences between satellite-derived and measured UV irradiances occur for the shortest wavelengths (e.g. Kazantzidis et al., 2006). With regard to the spectral aspect, Wuttke et al. (2003) emphasized the importance of spectral comparisons within validation studies to give hints about possible sources of uncertainties. Altogether, the mentioned studies show that the validation of the newly released OMI surface UV products is an important scientific task in this area of research. In addition a big question mark is the influence of ground inhomogeneity on the UV retrieval as well as the representativeness of the derived UV at one pixel. No study has been performed up to now to systematically study the inhomogeneity of UV within the area of one pixel and so to give also hints concerning the possible fluctuations within the area of one pixel. 
Within the present study we performed a validation of the satellite retrieved ground UV from OMI and in addition studied possible inhomogeneity within the area of one satellite pixel.

\section{Material and methods}

In this study we compared the surface UV indices derived from OMI with the ground-based measurements from 6 biometers in the city of Vienna and its surroundings over three months in spring and summer 2007.

\subsection{Ground-based measurements}

6 Biometers (Model 501, Solar Light) were used during a measurement campaign from the beginning of May until the end of July 2007. This type of detector has a spectral sensitivity which is similar - however, with small deviations - to the human erythema action spectrum and therefore it gives directly a signal related to the biological reaction. Due to the small mismatch between the sensitivity of the detector and the action spectrum a thorough calibration is necessary, which results in a calibration matrix in dependence on solar zenith angle and on atmospheric ozone content. The average angular response error ("cosine error") of the detector in dependence on the solar zenith angle is taken into account in the calibration matrix (Webb et al., 2006). Before deploying the detectors at their respective stations they were intercompared and homogenized during 5 days at one of these sites (Grossenzersdorf). The 6 stations BOKU (1), Strebersdorf (2), TGM (3), Grossenzersdorf (4), Bad Voeslau (5) and University of Veterinary Medicine (6) were chosen to get a representative picture of the UV irradiance distribution within an area of $30 \mathrm{~km}$. An overview over the location of the 6 stations in Vienna is provided in Fig. 1 while the station number, geographic position and altitude are given in Table 1. Two of the stations (TGM and University of Veterinary Medicine) are situated in the centre of the city where the largest turbidity is expected. Two of them (BOKU and Strebersdorf) are situated in the northern part of Vienna. BOKU is situated in a residential area in the 19th district of Vienna in an altitude of $256 \mathrm{~m}$ a.s.l. a little bit higher than the other stations. It could be expected that during some times of the day it may be situated over an eventual temperature inversion. Strebersdorf is situated at the northern limit of Vienna at $175 \mathrm{~m}$ a.s.l. Station Bad Voeslau (station 5) is - compared to the other stations - at a larger distance from BOKU (30 km south of Vienna) at an altitude of $286 \mathrm{~m}$ a.s.l. During the whole campaign, an automatic sun photometer (Precision Filter Radiometer, PMOD/WRC, Switzerland) was operated at station 1. It was mounted on a sun tracker and measured every minute the irradiance from the direct sun at the wavelengths $368 \mathrm{~nm}$, $412 \mathrm{~nm}, 500 \mathrm{~nm}$ and $862 \mathrm{~nm}$. From these data the aerosol optical depth (AOD) was calculated for each wavelength. Additionally at station 1 , hemispheric sky photographs were rou-

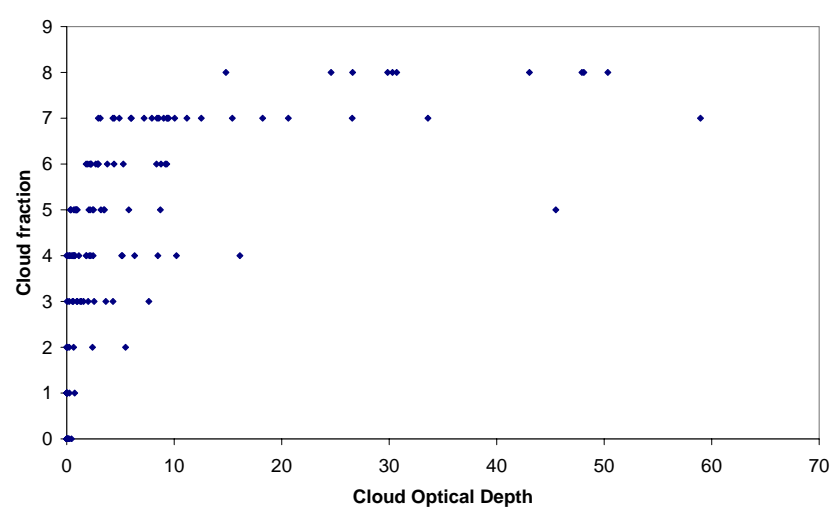

Fig. 2. Comparison of ground observations of cloudiness (cloud fraction in 1/8) (data from the Austrian Central Institute for Meteorology and Geodynamics ZAMG) with satellite determined cloud optical depth.

tinely taken every 15 min with a fish eye camera. It was used - in addition to data on sunshine duration and cloud fraction of the Austrian Central Institute for Meteorology and Geodynamics (ZAMG) - to check the cloudiness conditions for specific days. In general we could see that OMI cloud optical depths and ground observations of clouds were reasonably correlated (Fig. 2). At one station (3) in the centre of Vienna some additional measurements of AOD at 367, 500, 667 , and $867 \mathrm{~nm}$ were performed using a portable NOLL sun photometer. Since the measurement accuracy of the NOLL sun photometer at $367 \mathrm{~nm}$ is not as good as the accuracy of the PFR due to a low signal to noise ratio, only measurements of the NOLL sun photometer at $500 \mathrm{~nm}$ were used. The NOLL and the PFR sun photometer were intercompared before the measurements and also at the start of each measurement series. The mean bias between the readings of the two sun photometers at $500 \mathrm{~nm}$ was 0.007 and the Root mean square error was 0.037. An average measurement accuracy of the NOLL sun photometer of 0.037 (relative measurement uncertainty of $10 \%$ ) may therefore be expected.

\subsection{OMI-derived UV index}

The OMI surface UV algorithm is based on radiation transfer modelling, where the input parameters required by the model are derived from the OMI measurement data (Tanskanen et al., 2006). The algorithm is largely similar to the TOMS UV algorithm developed by NASA/GSFC (Krotkov et al., 1998, 2001). It first estimates the clear-sky surface irradiance using the total column ozone determined from the OMI measurement (Bhartia and Wellemayer, 2004), and the climatological surface albedo (Tanskanen, 2004). Next the clearsky value is adjusted by a transmittance factor that accounts for the attenuation of UV radiation by clouds and scattering aerosols. The attenuation factor is derived from the ratio of measured backscatter radiances and solar irradiances at 
Table 2. Mean bias of measured UV between the different ground stations under clear-sky (a), partly cloudy (b) and overcast (c) conditions. Stations in the left column are always compared to the stations mentioned in the upper row (e.g. for clear-sky conditions, average UV of station 2 is on average lower by $3 \%$ than UV of station 1 ).

\begin{tabular}{lrrrrrr}
\hline & \multicolumn{6}{c}{ average percentage difference of ground measurements } \\
\hline (a) clear-sky/Station code & 1 & 2 & 3 & 4 & 5 & 6 \\
1 & - & $+3 \%$ & $+2 \%$ & $+2 \%$ & $+5 \%$ & $+1 \%$ \\
2 & & - & $-1 \%$ & $-1 \%$ & $+2 \%$ & $-2 \%$ \\
3 & & & - & $\pm 0 \%$ & $+3 \%$ & $-1 \%$ \\
4 & & & & - & $+3 \%$ & $-1 \%$ \\
5 & & & & & - & $-4 \%$ \\
6 & & & & & & - \\
(b) partly cloudy / Station code & 1 & 2 & 3 & 4 & 5 & 6 \\
1 & - & $+2 \%$ & $\pm 0 \%$ & $+5 \%$ & $-6 \%$ & $+2 \%$ \\
2 & & - & $-2 \%$ & $+3 \%$ & $-8 \%$ & $\pm 0 \%$ \\
3 & & & - & $+5 \%$ & $-6 \%$ & $+2 \%$ \\
4 & & & & & $-11 \%$ & $-3 \%$ \\
5 & & & & & - & $+8 \%$ \\
6 & 1 & 2 & 3 & 4 & 5 & - \\
(c) overcast/Station code & - & $+18 \%$ & $+36 \%$ & $-21 \%$ & $-1 \%$ & $+6 \%$ \\
1 & - & - & $+18 \%$ & $-39 \%$ & $-19 \%$ & $-12 \%$ \\
2 & & & - & $-57 \%$ & $-37 \%$ & $-30 \%$ \\
3 & & & & - & $+20 \%$ & $+27 \%$ \\
4 & & & & & - & $+7 \%$ \\
5 & & & & & & - \\
6 & & & & & & \\
\hline
\end{tabular}

$360 \mathrm{~nm}$ assuming that clouds and aerosols are non-absorbing at this wavelength. This leads to an overestimation of surface UV irradiance when UV-absorbing aerosols such as smoke or desert dust are present. Additionally, boundary layer pollution aerosols cause overestimation of surface UV irradiance in urban areas. Future versions of the algorithm may correct for these effects.

Nominally the OMI surface UV algorithm calculates the erythemal irradiance for local solar noon. A modified version of the OMI surface UV algorithm was used to produce for the city of Vienna and its surroundings during the validation campaign of summer 2007 a special set of data that included the erythemal dose rates corresponding to the actual OMI measurement time. In the future these additional data are going to be added to the standard OMI surface UV product.

\section{Results}

\subsection{Comparison of ground measurement data}

The measured surface UV radiation was compared between all stations under three atmospheric conditions: clear-sky (sunshine duration equal to $100 \%$ of maximum possible sunshine), partly cloudy and overcast (Fig. 3a-c). BOKU (1) was chosen as a reference station for this comparison, since the additional measurements such as cloud cover monitoring and AOD measurements were performed there. These instantaneous values show that during partly cloudy conditions the difference of the UV between the stations is the largest.
The explanation for these larger fluctuations of UV within short time periods lies in a very quick alternation between sunshine and shading by the clouds.

\subsubsection{Clear-sky conditions}

Under clear-sky conditions the mean bias of UV-radiation at noon time at all stations to BOKU (1) were within $\pm 5 \%$ (see Table 2a) which is within the measurement uncertainty of the instruments $( \pm 5 \%)$ used within this study. These results show that under clear-sky conditions the atmospheric conditions within the study area are in most cases constant and the aerosol effect from urban pollution is not detectable because the results lie within the measurement uncertainty of the instruments. This conclusion is confirmed by the measurements of AOD performed in the city centre (station TGM) and at BOKU at the same time (Fig. 4), which show no distinctive difference between the AOD at both stations. The effect of AOD on UV irradiance was then analysed. We first performed a homogenization of all data by converting them to a constant level of total column ozone (300 DU) using following equation:

HomUVery $=$ UVery $*$ Corr

where UVery is the measured erythemal UV irradiance $\mathrm{Ho}$ $m U V e r y$ is the erythemal UV irradiance homogenized to column ozone of 300 DU. Corr is the homogenization factor and is calculated using following equation

Corr $=\operatorname{Mod} U V(300 D U) / \operatorname{Mod} U V(O 3)$ 


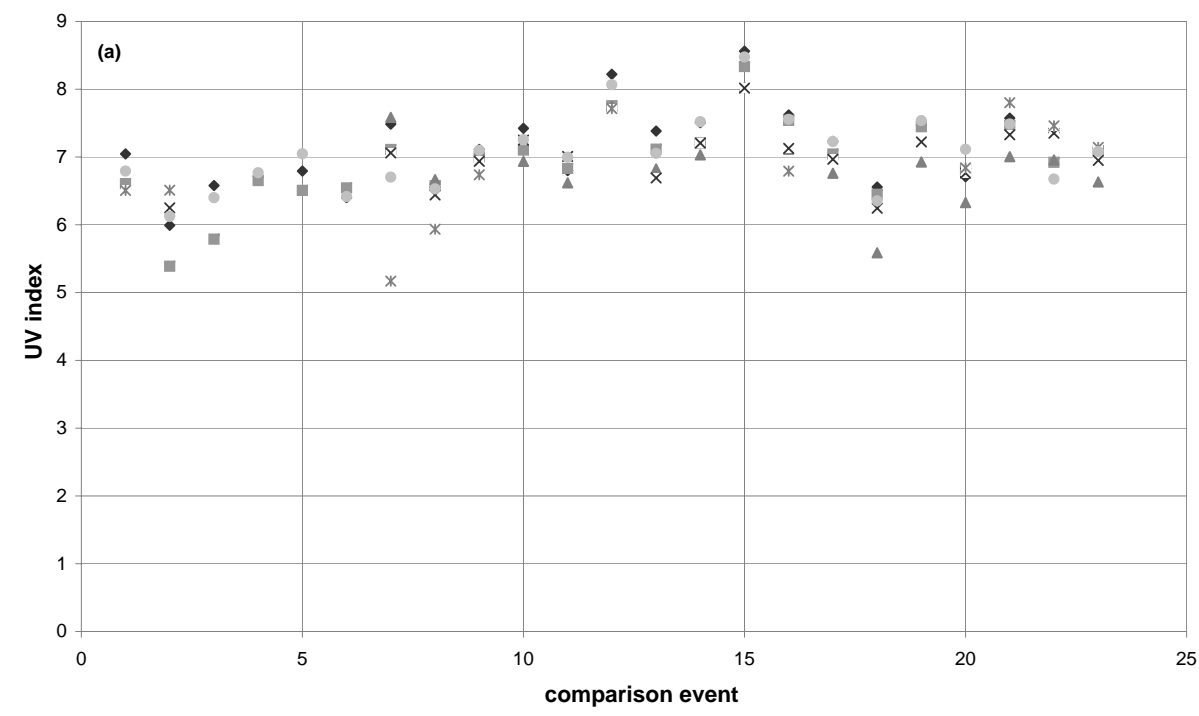

- BOKU $\square$ STREB $\triangle \mathrm{TGM} \times$ GED $*$ VOE $\bullet$ VETMED

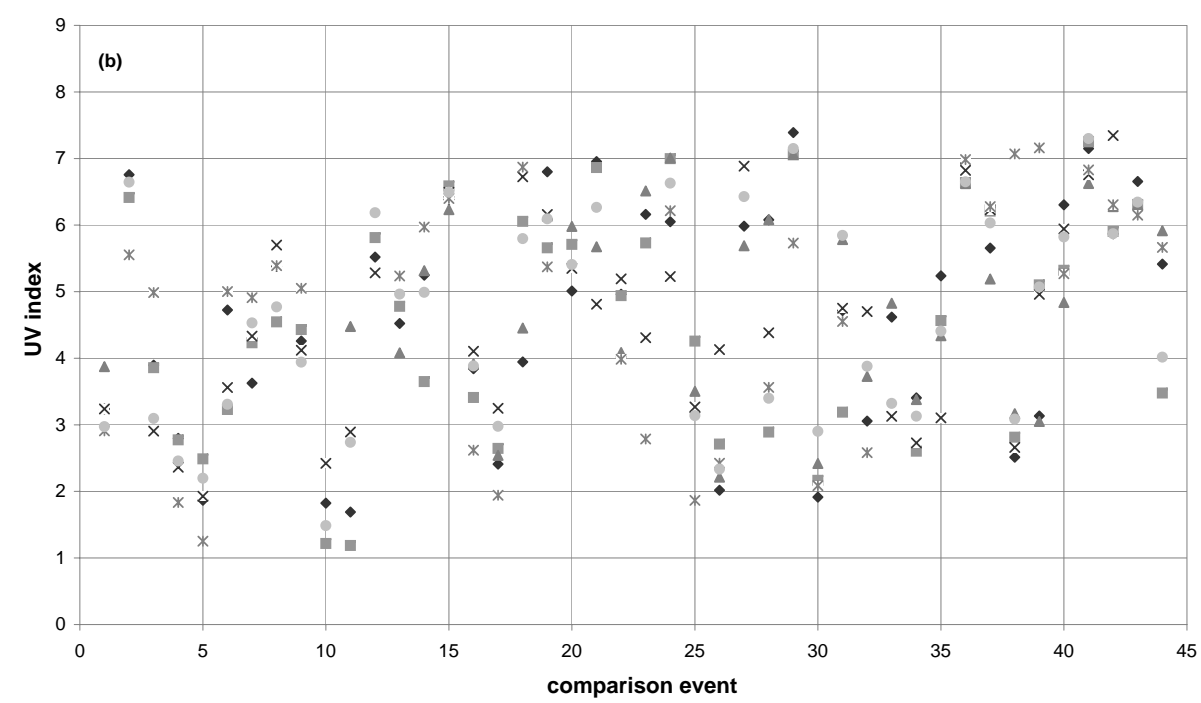

• BOKU $\backsim$ STREB $\triangle$ TGM $\times$ GED $*$ VOE คVETMED

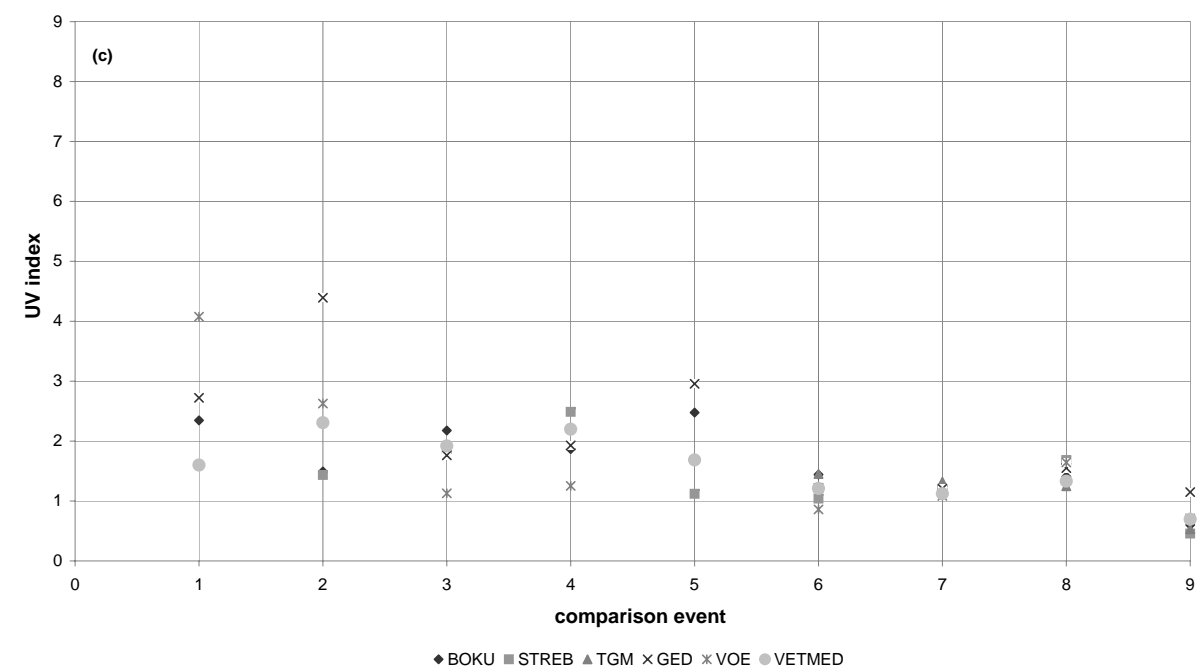

Fig. 3. Comparison of ground measurements performed at the 6 stations at noon during clear-sky conditions from May to July 2007. 


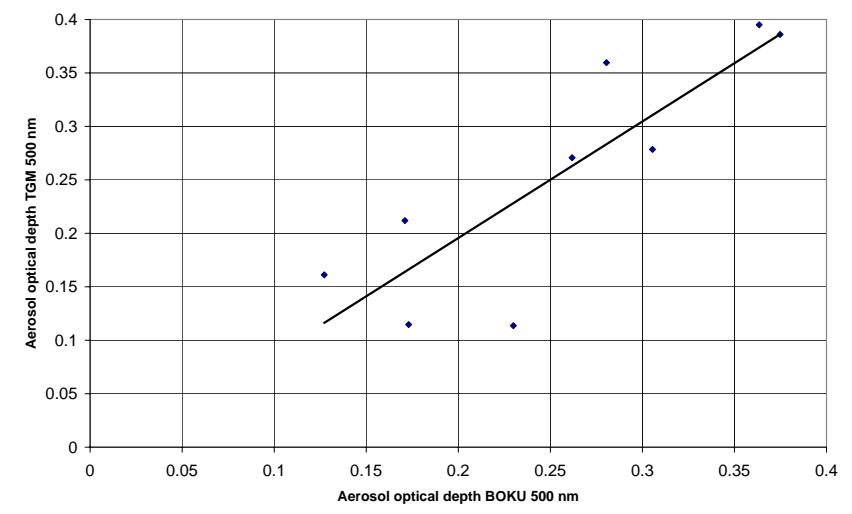

Fig. 4. Comparison of aerosol optical depth measurements at station BOKU (1) and at station TGM (3).

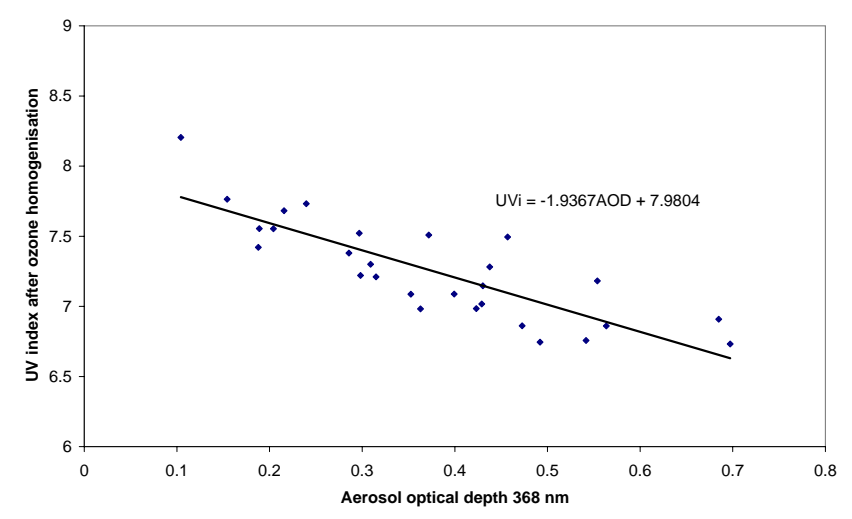

Fig. 5. Dependence of UV index on aerosol optical depth. A homogenisation was performed so that the UV index is referred to a column ozone value of $300 \mathrm{DU}$. Solar zenith angle is equal to $30 \pm 1^{\circ}$.

Where $\operatorname{Mod} U V(300 D U)$ is the erythemal UV irradiance calculated with the radiative transfer model SDISORT (Stamnes et al., 1988) using a column ozone value of $300 \mathrm{DU}$ and $\operatorname{ModUV}(\mathrm{O3})$ is erythemal UV irradiance calculated with the actual ozone amount. The column ozone values determined by OMI were taken for this homogenization. The dependence of erythemal UV on AOD is shown for station BOKU for a solar zenith angle of $30^{\circ}$ (approximately solar zenith angle during the overpass of the AURA satellite) in Fig. 5. There is a decrease in UV index of approximately $2.5 \%$ per increase in AOD at $368 \mathrm{~nm}$ of 0.1. Using OMI ozone for the homogenization may have contributed to the observed scattering around the regression line. Simulations performed with a radiative transfer model showed that sub-pixel variations in tropospheric ozone in the viennese area of up to $20 \mu \mathrm{g} / \mathrm{m}^{3}$ (which represents 10 to $20 \%$ of the tropospheric ozone values) may lead to uncertainties of the performed homogenization not larger than $\pm 2 \%$.
The (long-term) uncertainty of $\pm 5 \%$ of the biometers stated above - which explains the observed bias between the instruments - is in general, mainly related to the absolute irradiance scale used during the calibration.

According to Huber et al. (2002), maximum daily shortterm variations of the biometers may also, in some cases, reach $\pm 5 \%$. In general, they are however much smaller. If we assume however the worst case scenario, with an uncertainty of the UV biometers of $\pm 5 \%$, only (short-term) changes in AOD larger than 0.2 (which result in a change in UV larger than 5\%) may be reliably detected using UV measurements. The largest fluctuations in AOD during the campaign were in the order of magnitude of 0.6. Analysis of changes in AOD on satellite UV retrieval accuracy may therefore be performed since the expected effects of turbidity on UV irradiance are expected to be larger than the measurement uncertainty of about $\pm 5 \%$. Altogether, clear sky UV data showed no systematic difference between the stations. They showed however a distinctible dependence on AOD.

\subsubsection{Cloudy conditions}

For days with partial cloudiness (Fig. 3b), the magnitude of the UV index corresponds to the magnitude of the clear-sky UV index. The fluctuations of the measured UV index are however much larger. It is noticeable here, that the mean bias between the stations are larger than under clear-sky conditions. This can be explained mainly through differences in cloud cover and cloud reflection at the different measurement sites at the same time. The mean bias of all the stations to BOKU (Table 2b) lie within $\pm 6 \%$.

For overcast conditions (Fig. 3c) (sunshine duration equal $0)$ we obtained larger mean bias between the different stations and BOKU station (1). The absolute fluctuations of the UV index are also much larger. The mean bias between the stations 5 and 6 to BOKU (Table 2c) lie within $\pm 6 \%$ which is almost within the measurement uncertainty of the used instruments. Larger deviations in comparison to BOKU can be found for stations $3(+36 \%), 4(-21 \%)$, and $2(+18 \%)$. Under overcast conditions the mean bias between the different stations is even larger than for days with partial cloudiness (see Table 2c). This can be explained through differences in cloud types and cloud properties. The largest difference between BOKU (1) and TGM (3) situated in the centre of the city with an altitude difference of $80 \mathrm{~m}$ may be explained by low altitude fog layers connected with ground inversions.

\subsubsection{Subpixel variation}

The variability within one pixel during cloudy conditions was then adressed. The size of the satellite pixel ranges approximately between $13 \times 24 \mathrm{~km}$ and $50 \times 50 \mathrm{~km}$ depending on the satellite angle of view, which approximately corresponds to our study area. The variability $V$ of the station $x$ 

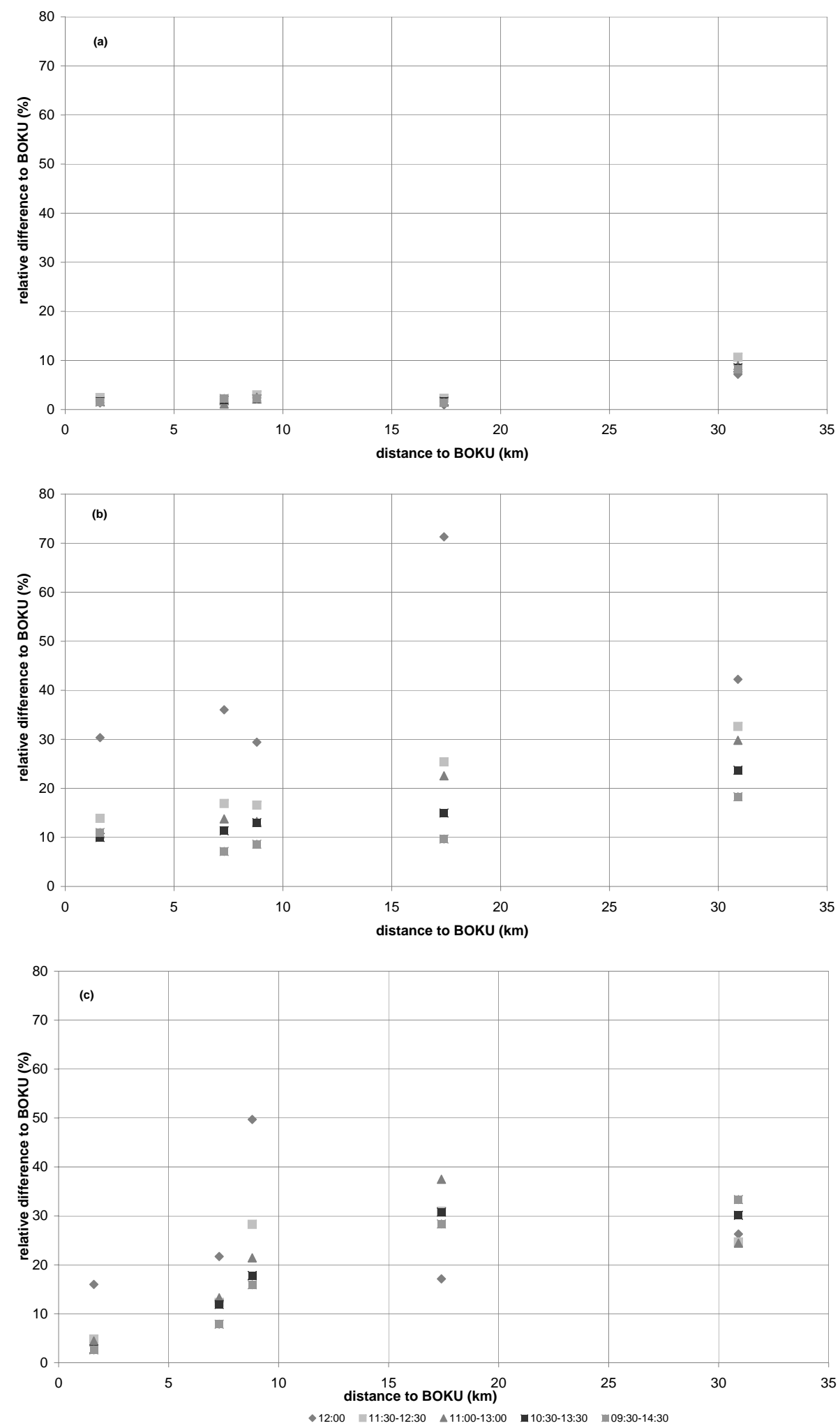

Fig. 6. Variability of UV index compared to BOKU UV index as a function of distance for different averaging intervals. Figure 6a shows variability for clear-sky, Fig. 6b for partly cloudy and Fig. 6c for overcast conditions. 12:00 is for instantaneous values, 11:30-12:30 is average from 11:30 Local solar time (LST) to 12:30 LST, 11:00-13:00 is average from 11:00 LST to 13:00 LST, 10:30-13:30 is average from 10:30 LST to 13:30 LST, 09:30-14:30 is average from 09:30 LST to 14:30 LST. The distances correspond to the stations as denoted in Table 3 . 
Table 3. Distance of the stations to BOKU.

\begin{tabular}{ll}
\hline Station (number) & $\begin{array}{l}\text { Distance } \\
\text { to BOKU in km }\end{array}$ \\
\hline Strebersdorf (2) & 8.8 \\
TGM (3) & 1.6 \\
Grossenzersdorf (4) & 17.4 \\
Bad Voeslau (5) & 30.9 \\
University of Veterinary Medicine (6) & 7.3 \\
\hline
\end{tabular}

around an average ratio (average mean bias) of the station to BOKU was calculated using following equation:

$V($ station $x)=\operatorname{abs}\left(\sum(R i-\right.$ Rmean $\left.) * 100\right) / n$

Where $R i$ is the momentary or the averaged ratio over a given time intervall $(1 \mathrm{~h}, 2 \mathrm{~h}, 3 \mathrm{~h})$ of the UV index at station $x$ to the $\mathrm{UV}$ index at station BOKU Rmean is the average of all Ri of station $x$, while $n$ is the number of measurements used.

Figure 6 shows the variability $V$ as a function of the distance from BOKU station for different time intervals. Each distance corresponds to a station which is shown in Table 3. The variability increases with increasing distance from BOKU. In general the variability to BOKU decreases when UV index is averaged over a longer time period. An exception is variability $V$ for total overcast conditions and for distances larger than $17 \mathrm{~km}$, where averaging the UV index does not contribute to a decrease of the variability. The explanation may lie in different cloud optical characteristics due to the large distance which may be the most dominant factor. The strongest decrease in variability at most of the stations is obtained when instantaneous values are averaged over a $1 \mathrm{~h}$ interval. The difference of variability between $1 \mathrm{~h}$ mean, $2 \mathrm{~h}$ means and $3 \mathrm{~h}$ means is less pronounced.

Altogether the results from the different measurement sites show that under clear-sky conditions short term fluctuations of UV between the stations were below $3 \%$ within a radius of $20 \mathrm{~km}$ (Fig. 6a). One single value (as provided by the satellite) is representative for the area of one satellite pixel (approximately $20 \mathrm{~km}$ ). For partly cloudy or overcast conditions (Fig. 6b and 6c) it has to be taken into account that atmospheric conditions can be quite heterogeneous within the area of one satellite pixel (compare Table $2 \mathrm{~b}$ and c). Taking this into account the representativeness of one single measurement is much weaker than under clear-sky conditions. The variability of stations within a radius of $10 \mathrm{~km}$ of BOKU station is however below 20 per cent if 3 hourly averages are used.

3.2 Comparison of ground measurement data with satellite observations

In this section a comparison of the OMI-derived UV index with ground measurements under different atmospheric conditions (clear-sky, partly cloudy and overcast) is shown. During the entire measurement campaign we had totally 77 OMI-overpasses available which were within the needed geographic neighborhood to the measurement sites used within the campaign. In total we had the opportunity to compare OMI-data with ground measurements 9 times under overcast conditions, 23 times under clear-sky conditions and 45 times under partly cloudy conditions.

\subsubsection{Comparison for clear-sky conditions}

Figure 7a shows the comparison of satellite data with ground measurements under clear-sky conditions. In general the satellite slightly overestimated the ground UV. The difference between the satellite UV values and the ground measured value lies between -10 and $+50 \%$ (see also Fig. 8). The average difference between the satellite UV-value and the ground measured value is $+16 \%$ at BOKU University (1), $+15 \%$ at Bad Voeslau (5) and Grossenzersdorf (4), $+11 \%$ at University of Veterinary Medicine (6), $+14 \%$ at the station Strebersdorf (2) and $+18 \%$ at TGM. These results agree with the overestimation of satellite derived UV-data over urban areas (without snow cover) under clear-sky conditions in the range of $0 \%$ to $+40 \%$ reported in several papers (e.g. Kalliskota et al., 2000; McKenzie et al, 2001b; Fioletov et al., 2002; Chubarova et al., 2002; Cede et al., 2004; Arola et al., 2005; Kazantzidis et al., 2006). Figure 7a gives a comparison of all ground measurements with the corresponding OMI UV-data under clear-sky conditions. Figure 8 shows the ratio of OMI erythemal UV to the ground measured UV at station BOKU (1) as a function of the AOD at $368 \mathrm{~nm}$ measured by the PFR sun photometer. The uncertainty of the OMI ratio - which results from the measurement uncertainty of the UV biometers - is also shown in the figure. The ratio increases from 1.05 for an AOD of 0.15 to 1.35 for an AOD of 0.6. (if one of the values around 1.45 is considered as an outlier). These findings agree with results of other studies (e.g. by Arola et al., 2005).

\subsubsection{Comparison for partly cloudy conditions}

The comparison of OMI-products with ground measurements under partly cloudy conditions is shown in Fig. 7b. Since instantaneous values seem not to be able to characterize the UV levels in the area of one satellite pixel (Sect. 3.1), hourly averaged values of the UV index were used for this comparison to OMI. The ratios of OMI UV to ground measurements still lie between 0.5 and 4 . The satellite UV-values are on average higher by $25 \%$ at the station Grossenzersdorf, $27 \%$ at University of Veterinary Medicine, $32 \%$ at Bad Voeslau, $24 \%$ at the station TGM, 30\% at BOKU and $37 \%$ at station Strebersdorf. The median of the differences of OMI to ground UV stations is with values between 12 and $26 \%$ lower since it does not include outliers. 


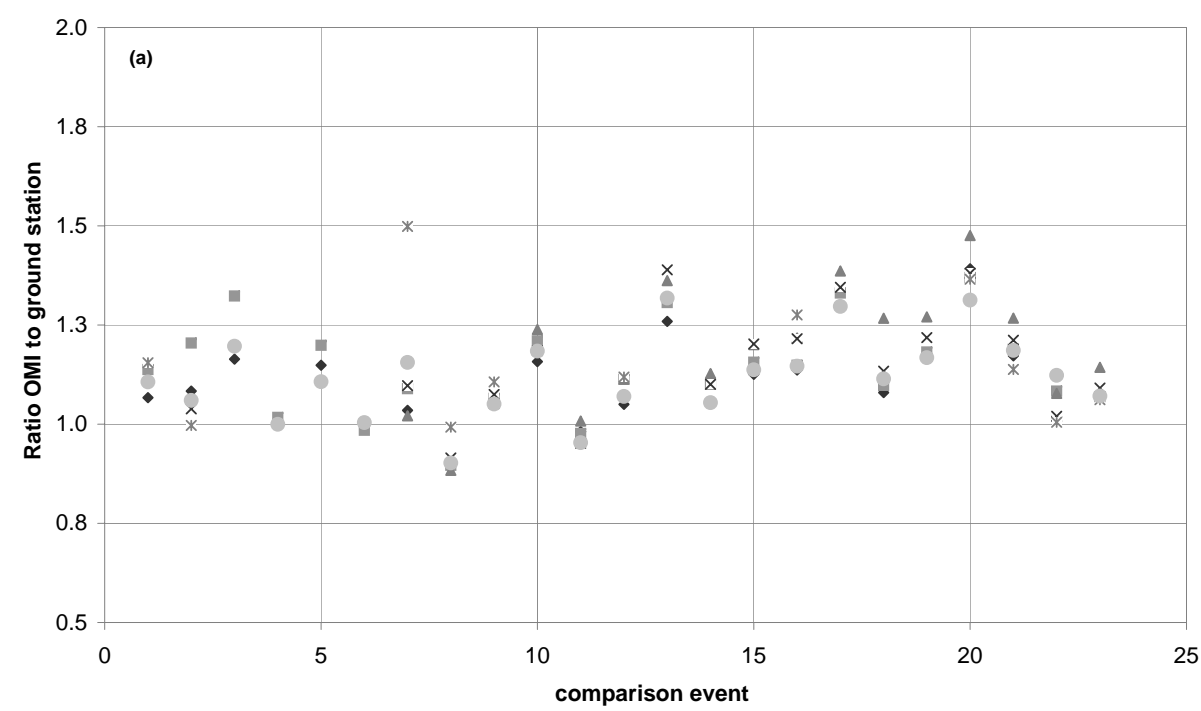

• BOKU $\backsim$ STREB $\triangle$ TGM $\times$ GED $*$ VOE คVETMED

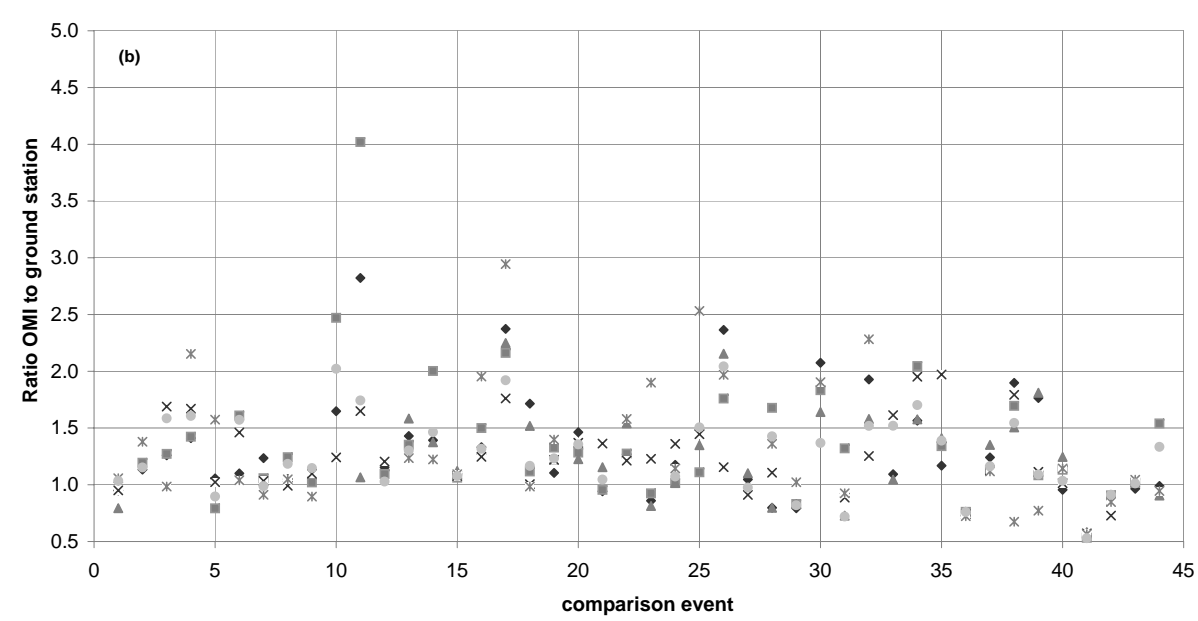

•BOKU $\because$ STREB $\triangle$ TGM $\times$ GED $*$ VOE •VETMED

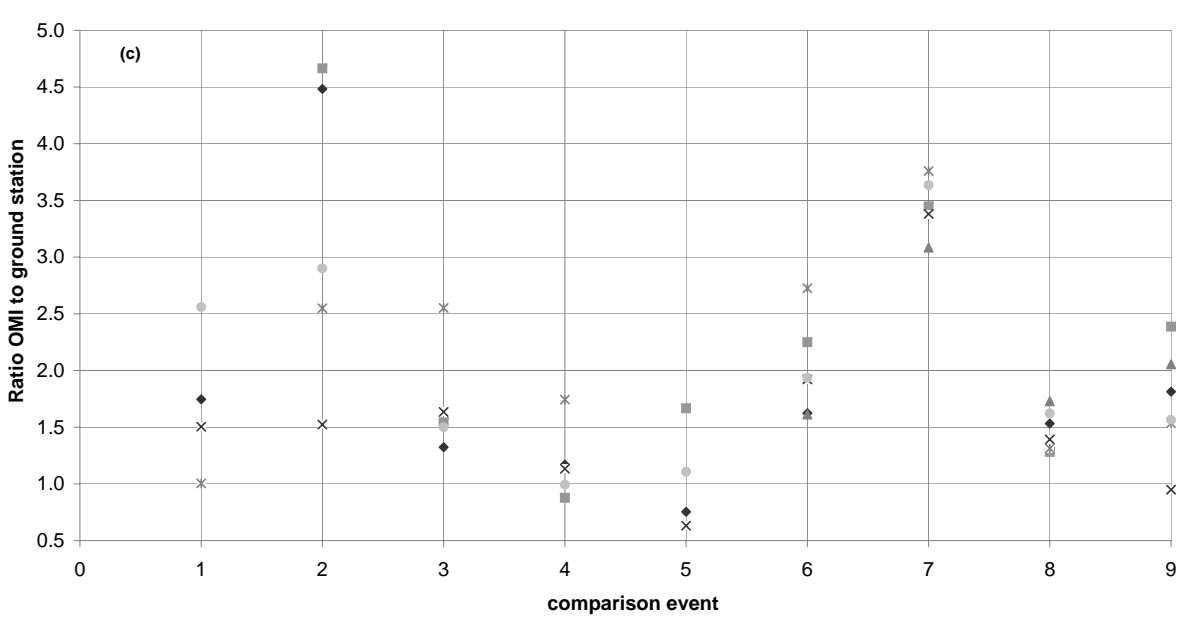

•BOKU $\backsim$ STREB $\triangle$ TGM $\times$ GED $*$ VOE $\odot$ VETMED

Fig. 7. Ratios of OMI observations to ground measurements during clear-sky (a), partly cloudy (b) and overcast conditions (c) from May to July 2007. Following results of Sect. 3.1, for the clear-sky comparisons instantaneous values and for cloudy conditions $1 \mathrm{~h}$ averages were used. STREB is for Strebersdorf, GED for Grossenzersdorf, VOE for Bad Voeslau and VETMED for University of Veterinary Medicine 


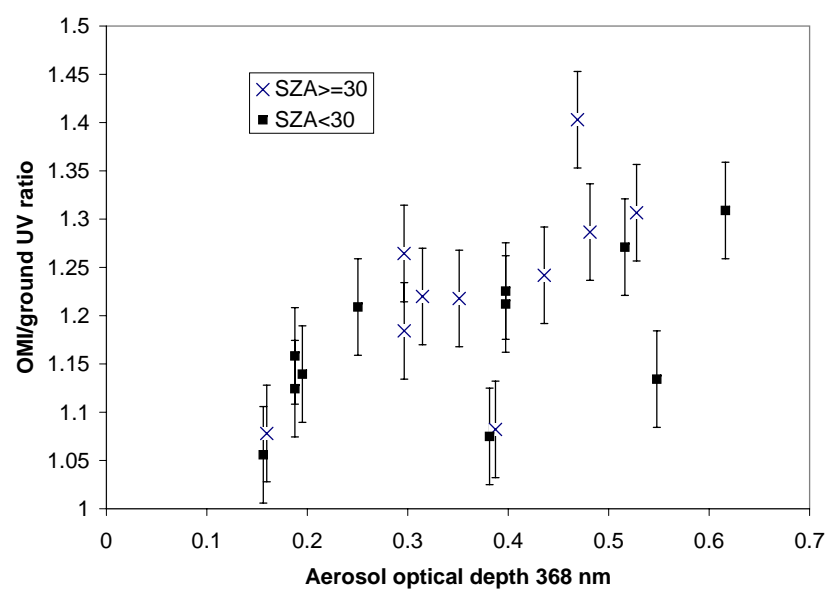

Fig. 8. Ratio of satellite retrieved to ground measured (BOKU station) erythemal UV for clear-sky conditions. The ratio is shown for solar zenith angles (SZA) larger and lower than $30^{\circ}$ The errors bars correspond to the uncertainty of the OMI ratio, which results from the measurement uncertainty of the UV biometers.

\subsubsection{Comparison for overcast conditions}

Comparison of OMI satellite data with ground measurements is shown in Fig. 7c. The analysis of the datasets shows a large disagreement between OMI and ground observations under overcast conditions. Here the ratios of OMI UV to ground measurements lie between 0.6 and 4.6. On average the OMI instrument overestimates the UV-values by more than $50 \%$. The average difference between the satellite derived data and the ground observations is $112 \%$ at TGM, $115 \%$ at Bad Voeslau, $98 \%$ at University of Veterinary Medicine, $98 \%$ at BOKU, 56\% at Grossenzersdorf and 126\% in Strebersdorf. An outlier may however strongly influence the average ratio when only data from 9 overpasses are used for the statistics. For TGM (3) only 4 days were available because of missing data. The median may therefore in this case be more suited to characterize the discrepancy between satellite and ground UV. The median of the differences is $+50 \%$ at Grossenzersdorf (4), $+61 \%$ for BOKU (1) and University of Veterinary Medicine (6) but $+89 \%$ at TGM (3) $+98 \%$ at Strebersdorf (2) and still $+115 \%$ at Bad Voeslau (5).

Altogether, these results indicate an overestimation of simulated ground UV by the OMI UV algorithm. An improvement of the algorithm for overcast conditions is necessary to improve the quality and usability of satellite UV datasets also under these atmospheric conditions.

\section{Discussion and conclusion}

Under clear-sky conditions the OMI UV-values overestimate those measured at ground on average by 11 to $18 \%$. A more profound analysis shows that the discrepancy between OMI and ground UV increases with increasing turbidity. These results confirm the overestimation of ground UV by TOMS and OMI which was found in previous studies (Kalliskota et al., 2000; McKenzie et al., 2001b; Fioletov et al., 2002; Chubarova et al., 2002; Cede et al., 2004; Arola et al., 2005; Kazantzidis et al., 2006; Tanskanen et al., 2007). It also confirms findings by Arola et al. (2005) which showed the increase of the discrepancy between OMI and ground measurements with increasing AOD. This dependence on AOD is attributed to the fact that aerosols absorption characteristics are not taken into account in the OMI algorithm.

Under partly cloudy and overcast conditions some improvement of the UV-algorithm or some additional routines in the OMI scheme are needed to get a better fit between satellite data and ground observations. While under partly cloudy conditions the satellite UV-values are, on average, $24 \%$ to $37 \%$ higher than the ground observations, the ratio OMI to ground UV becomes even larger for overcast conditions. The satellite overestimates the observed ground values by more than $50 \%$.

For an improvement of the OMI UV-algorithms under overcast conditions more data on cloud optical depth would be needed to test the OMI cloud optical depth retrieval algorithms.

Concerning the representativeness of one UV value for one satellite pixel, one value may be sufficient to characterize the UV levels of the Viennese area approx. $30 \times 30 \mathrm{~km}$ under clear-sky conditions. Under partly cloudy conditions the average bias between the stations are within $\pm 10 \%$. Absolute difference in UV index at a given time of the day may however reach values of up to almost 5 (see Fig. 3b). Under overcast conditions absolute difference in UV index between the stations as high as 3 may be reached.

Altogether the results of this study indicate that currently ground-based measurement networks cannot be replaced by the use of satellite data: first because of their uncertainties, especially under cloudy and overcast conditions, second because of their resolution in space and time that would need to be comparable to ground-based measurements. Resolution in time will probably remain a problem in the near future. Satellite based UV measurements have however a great value due to their global coverage and providing data over regions, where ground-based measurements do not exist or cannot be made such as over the oceans and in remote areas. In regions where ground-based data are available, satellite based data may be merged with ground-based data, as soon as their uncertainties will have been significantly reduced to improve spatial data coverage. Ground-based measurements will also remain to be a valuable data source for further validation of satellite-based data and improvement of their retrieval algorithms. 
Acknowledgements. The Dutch-Finnish built OMI instrument is part of the NASA EOS Aura satellite payload. The OMI project is managed by NIVR and KNMI in the Netherlands. We thank the OMI International Science Team for the satellite data used in this study. The OMI surface UV data were obtained from the NASA Aura Validation Data Center (AVDC). This work was performed in the framework of the International ESA/KNMI/NIVR OMI "Announcement of Opportunity for Calibration and Validation of the Ozone Monitoring Instrument", providing early access to provisional OMI data sets and guidance to public OMI data. Further the authors want to thank the Austrian Central Institute for Meteorology and Geodynamics (ZAMG) for providing datasets on sunshine duration and cloud properties used in this study.

The PFR-sunphotometer was kindly provided by the Institute for Meteorology and Geophysics, University of Innsbruck, Austria. This work was funded by the Austrian Research Promotion Agency (FFG), within the scope of the projects OMI-ASAP Validation of Ozone Monitoring Instrument (OMI) Ground UV Products (OMI-ASAP).

Edited by: J. Groebner

\section{References}

Arola, A., Kazadzis, S., Krotkov, N., Bais, A., Gröbner, J., and Herman, J. R.: Assessment of TOMS UV bias due to absorbing aerosols, J. Geophys. Res., 110(D23211), doi:10.1029/2005JD005913, 2005.

Bhartia, P. K. and Wellemeyer, C.: TOMS version 8 Algorithm Theoretical Basis Document, http://toms.gsfc.nasa.gov, November 24, 2004.

Cede, A., Luccini, E., Nuñez, L., Piacentini, R. D., Blumthaler, M., and Herman, J.: TOMS derived erythemal irradiance versus measurements at the stations of the Argentine UV Monitoring Network, J. Geophys. Res., 109(D08109), doi:10.1029/2004JD004519, 2004.

Chubarova, N. E., Yurova, A. Y., Krotkov, N. A., and Herman, J. R.: Comparisons between ground measurements of broadband ultraviolet (300 to $380 \mathrm{~nm}$ ) and total ozone mapping spectrometer ultraviolet estimates at Moscow from 1979 to 2000, Opt. Eng., 41(12), 2070-3081, 2002.

Fioletov, V. E., Kerr, J. B., Wardle, D. I., Krotkov, N., and Herman, J. R.: Comparison of Brewer ultraviolet irradiance measurements with total ozone mapping spectrometer satellite retrievals, Opt. Eng., 41(12), 3051-3061, 2002.

Herman, J. R., Krotkov, N. A., Celarier, E., Larko, D., and Labow, G.: Distribution of UV radiation at the Earth's surface from TOMS measured UV-backscattered radiances, J. Geophys. Res., 104, 12 059-12 076, doi:0.1029/1999JD900062, 1999.

Huber M., Blumthaler, M., Schreder, J., Bais, A., and Topaloglou, C.: Effect of ambient temperature on Robertson-Berger type erythemal dosimeters, Appl. Optics, 41, 4273-4277, 2002.

Kalliskota, S., Kaurola, J., Taalas, P., Herman, J. R., Celarier, E., and Krotkov, N.: Comparison of the daily UV doses estimated from Nimbus7/TOMS measurements and ground-based spectroradiometric data, J. Geophys. Res., 105, 5059-5067, doi:10.1029/1999JD900926, 2000.
Kaurola, J., Taalas, P., Koskela, T., Borkowski, J., and Josefsson, W.: Long-term variations of UV-B doses at three stations in northern Europe, J. Geophys. Res., 105(D16), 20 813-20 820, doi:10.1029/2000JD900258, 2000.

Kazantzidis, A., Bais, A. F., Gröber, J., Herman, J. R., Kazadzis, S., Krotkov, N., Kyrö, E., den Outer, P. N., Garane, K., Görts, P., Lakkala, K., Meleti, C., Slaper, H., Tax, R. B., Turunen, T., and Zerefos, C. S.: Comparison of satellite-derived UV irradiances with ground-based measurements at four European stations, J. Geophys. Res., 111, D13207, doi:10.1029/2005JD006672, 2006.

Koepke, P., De Backer, H., Bais, A., Curylo, A., Eerme, K., Feister, U., Johnsen, B., Junk, J., Kazantzidis, A., Kryscin, J., Lindfors, A., Olseth, J. A., den Outer, P., Pribullova, A., Schmalwieser, A., Slaper, H., Staiger, H., Verdebout, J., Vuilleumier, L., and Weihs, P.: Modelling solar UV radiation in the past: algorithms and input data, Proc. SPIE, 6362, 1-11, 2006.

Krotkov, N. A., Bhartia, P. K, Herman, J. R., Ahmad, Z., and Fioletov, V.: Satellite estimation of spectral surface UV irradiance 2: Effect of horizontally homogeneous clouds and snow, J. Geophys. Res., 106, 11743-11759, doi:10.1029/2000JD900721, 2001.

Krotkov, N. A., Herman, J. R., Bhartia, P. K., Seftor, C., Arola, A., Kaurola, J., Kalliskota, S., Taalas, P., and Geogdzhaev, I. V.: Version 2 total ozone mapping spectrometer ultraviolet algorithm: problems and enhancements, Opt. Eng., 41(12), 30283039, 2002.

Levelt, P. F., Hilsenrath, E., Leppelmeier, G. W., Van den Oord, G. H. J., Bhartia, P. K., Tamminen, J., De Haan, J. F., and Veefkind, J. P.: Scientific Objectives of the Ozone Monitoring Instrument, IEEE T. Geosci. Remote, 44(5), 1199-1208, 2006.

Lindfors, A. and Vuilleumier, L.: Erythemal UV at Davos (Switzerland), 1926-2003, estimated using total ozone, sunshine duration, and snow depth, J. Geophys. Res., 110, D02104, doi:10.1029/2004JD005231, 2005.

McKenzie, R. L., Seckmeyer, G., Bais, A. F., Kerr, J. B., and Madronich, S.: Satellite retrievals of erythemal UV dose compared with ground-based measurements at northern and southern midlatitudes, J. Geophys. Res., 106, 24 051-24 062, doi:10.1029/2001JD000545, 2001b.

National Radiological Protection Board: Health effects from ultraviolet radiation: Report of an advisory group on non-ionising radiation, Doc. NRP, 13, 1, UK, 2002.

Rieder, H. E., Holawe, F., Simic, S., Blumthaler, M., Krzysćin, J. W., Wagner, J., Schmalwieser, A., and Weihs, P.: Reconstruction of erythemal UV-levels for two stations in Austria: a comparison between alpine and urban regions, Atmos. Chem. Phys. Discuss., 8, 957-994, 2008, http://www.atmos-chem-phys-discuss.net/8/957/2008/.

SCOPE: Effects of Increased Ultraviolet Radiation on Global Ecosystems, Scientific Committee on Problems of the Environment (SCOPE), 51 bd de Montmorency, 75016 Paris, France, 1993.

SCOPE, Effects of Increased Ultraviolet Radiation on Biological Systems, Scientific Committee on Problems of the Environment (SCOPE), 51 bd de Montmorency, 75016 Paris, France, 1992.

Stamnes, K., Tsay, S. C., Wiscombe, W., and Jayaweera, K.: Numerically stable algorithm for discrete-ordinate-method radiative transfer in multible scattering and emitting layered media, Appl. Optics, 27, 2502-2509, 1988. 
Tanskanen, A.: Lambertian Surface Albedo Climatology at $360 \mathrm{~nm}$ from TOMS Data Using Moving Time-Window Technique, Proc. XX Quadr. Oz. Symp., 1-8 June, Kos, Greece, 2004.

Tanskanen, A., Krotkov, N. A., Herman, J. R., and Arola, A.: Surface Ultraviolet Irradiance from OMI, IEEE T. Geosci. Remote, 44, 1267-1271, 2006.

Tanskanen, A., Lindfors, A., Määttä, A., Krotkov, N., Herman, J., Kaurola, J., Koskela, T., Lakkala, K., Fioletov, V., Bernhard, G., McKenzie, R., Kondo, Y., O’Neill, M., Slaper, H., DenOuter, P., Bais, A. F., and Tamminen, J.: Validation of daily erythemal doses from ozone Monitoring Instrument with groundbased UV measurement data, J. Geophys. Res., 112, D24S44, doi:10.1029/2007JD008830, 2008.
United Nations Environment Program (UNEP): Environmental effects of ozone depletion: 1998 assessment, Nairobi, Kenya, 1998.

Webb, A., Gröbner, J., and Blumthaler, M.: A Practical Guide to Operating Broadband Instruments Measuring Erythemally Weighted Irradiance, Office for Official Publications of the European Communities, Luxembourg, 21 pp., 2006, ISBN 92-8980032-1, 2006.

Wuttke, S., Verdebout, J., and Seckmeyer, G.: An improved algorithm for satellite-derived UV radiation, Photochem. Photobiol., 77(1), 52-57, 2003.

World Meteorological Organization (WMO): Scientific Assessment of Ozone Depletion: 1994, Global Ozone Research and Monitoring Project, WMO Rep. N 37, Geneva, 1995. 